\title{
Three Korean patients with Cantú syndrome caused by mutations in $A B C C 9$ and their clinical manifestations
}

\author{
Jin Hee Jang, Jung Min Ko ${ }^{1,2}$, , Sei Won Yang, Jong Hee Chae', and Eun Jung Bae ${ }^{1}$ \\ 'Department of Pediatrics, Seoul National University Children's Hospital, Seoul, Korea \\ ${ }^{2}$ Research Coordination Center for Rare Diseases, Seoul National University Hospital, Seoul, Korea
}

\begin{abstract}
Cantú syndrome (CS, OMIM 239850) is a very rare autosomal dominantly inherited genetic disease characterized by congenital hypertrichosis, neonatal macrosomia, a distinct facial features such as macrocephaly, and cardiac defects. Since the first description by Cantú et al. in 1982, about 50 cases have been reported to date. Recently, two causative genes for CS has been found by using exome sequencing analyses: ABCC9 and KCNJ8. Most cases of clinically diagnosed CS have resulted from de novo mutations in $A B C C 9$. In this study, we report three independent Korean children with CS resulting from de novo ABCC9 mutations. Our patients had common clinical findings such as congenital hypertrichosis, distinctive facial features. One of them showed severe pulmonary hypertension and hypertrophic cardiomyopathy, which require medical treatment. And, two patients had a history of patent ductus arteriosus. Although two of our patients had shown early motor developmental delay, it was gradually improved during follow-up periods. Although CS is quite rare, there are the concerns about development of various cardiac problems in the lifetime. Therefore, an accurate diagnosis followed by appropriate management and genetic counseling should be provided to CS patients.
\end{abstract}

Key words: Cantú syndrome, Hypertrichosis, Macrocephaly, Hypertrophic cardiomyopathy, ABCC9.

\section{Introduction}

Cantú syndrome (CS, OMIM 239850) is an extremely rare genetic disease that only about 50 cases have been reported worldwide. CS is characterized by congenital hypertrichosis, coarse facial features, neonatal macrosomia, cardiomegaly and skeletal abnormalities [1]. Affected individuals show great variability in clinical manifestations and severity. In earlier reports, the diagnosis of CS had been entirely based on clinical findings. Since the first description of two affected siblings and two unrelated patients by Cantú et al. [2] in 1982, CS was presumed to be an autosomal recessive disorder at first.
However, autosomal dominant inheritance was subsequently supported by two further reports of familial cases [3,4]. In 2012, ABCC9 was identified as the first causative gene for CS by exome sequencing analysis $[5,6]$. In 2013, de novo mutations of KCNJ8 were described as the second cause of CS in two ABCC9 mutation-negative CS patients [7]. ATP-sensitive potassium channels are composed of inward-rectifying potassium channel pore-forming subunits and regulatory sulfonylurea receptor subunits. These channels couple metabolism to excitability in multiple tissues. ABCC9 and KCNJ8 encode the channel regulator, SUR2, and the channel pore-forming subunits, Kir6.1 respectively. Most cases of clinically diagnosed CS have resulted

\footnotetext{
Received: 16 May 2016, Revised: 10 June 2016, Accepted: 12 June 2016, Published: 31 December 2016

${ }^{*}$ Corresponding author: Jung Min Ko, M.D., Ph.D.

Department of Pediatrics, Seoul National University Children's Hospital, 101 Daehak-ro, Jongno-gu, Seoul 03080, Korea.

Tel: +82-2-2072-3570, Fax: +82-2-743-3455, E-mail:jmko@snu.ac.kr

Conflict of interest: We declare that we do not have any conflicts of interests.

(c) This is an open-access article distributed under the terms of the Creative Commons Attribution Non-Commercial License (http://creativecommons.org/licenses/by-nc/4.0/) which permits unrestricted non-commercial use, distribution, and reproduction in any medium, provided the original work is properly cited.

(c) Copyright 2016 by the Korean Society of Medical Genetics

www.e-kjgm.org
} 
from de novo mutation of $A B C C 9$, and all identified $A B C C 9$ mutations altered amino acids in or close to the transmembrane domains [5]. Therefore, CS is thought to be a member of the potassium channelopathies $[5,8]$. However, the impacts of ABCC9 and KCNJ8 mutations on its clinical manifestations of CS remains unclear yet.

In Korea, there has been only one fatal case of CS presenting with bronchopulmonary dysplasia and pulmonary hypertension [9]. In this report, we describe the three independent Korean children with CS confirmed by de novo mutations of $A B C C$.

\section{Case}

\section{Patient 1}

Patient 1 is the first child of healthy Korean parents. He was delivered by Cesarean section due to polyhydramnios at 36 weeks and two days of gestation and his birth weight was 3.84 $\mathrm{kg}$ (>97th percentile). Just after birth, he was admitted to the neonatal intensive care unit due to respiratory difficulty and cared as transient tachypnea of newborn. Echocardiography showed a patent ductus arteriosus (PDA) and mild mitral insufficiency. Surgical ligation of PDA was performed at the age of 1 week. At the age of 15 months, he visited an outpatient clinic in our hospital because of profuse sweating and generalized hypertrichosis. He showed frontal bossing, low nasal bridge, low hair line on the forehead and generalized hypertrichosis (Fig. 1). His motor development was also delayed, and he was unable to sit alone or crawl at that time. The results of chromosome analysis using peripheral blood and the level of urine glycosaminoglycan were normal. Along with physiotherapy, he could walk alone at the age of 17 months. His language development was normal. Treatment with spironolactone and cyproterone acetate for 6 months had no effect to improve hirsutism.

At the age of 4 years and 5 months, he was referred to medical genetics clinic for genetic evaluation of generalized hirsutism and macrocephaly. The height and weight of the boy were $116 \mathrm{~cm}$ (>97th percentile) and $21.9 \mathrm{~kg}$ (90th-95th percentile), respectively and his head circumference was $56.1 \mathrm{~cm}$ (>97th percentile). His showed generalized excessive hirsutism, coarse face, arched palate, narrow forehead, and pectus carinatum deformity of the chest. Calvarial vault thickening was observed on skull X-rays. However, there was no further skeletal abnormality on skeletal survey or brain parenchymal
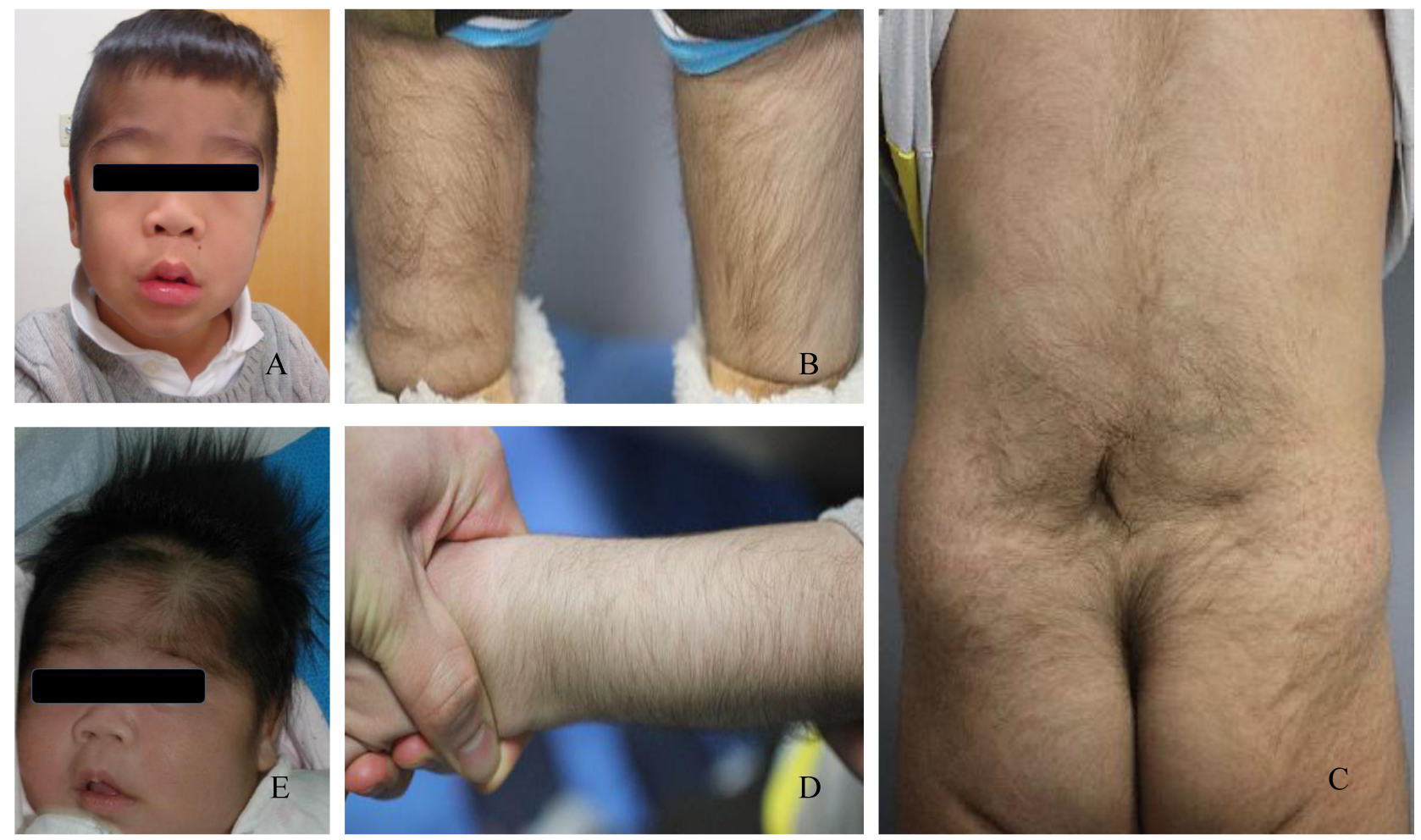

Fig. 1. Medical photography shows the typical features of Cantu syndrome. Facial photographs of Patient 1 (A) and Patient 2 (E) show coarse facial appearance, including hirsutism of forehead, a broad nasal bridge, a short nose, and a long philtrum. The excessive hair growth hirsutism over both lower legs (B), the lower back (C), and the forearms (D) are observed in Patient 1. 
abnormalities on the brain magnetic resonance imaging findings. CS was suspected based on the medical history and clinical findings including somatic overgrowth and hirsutism. Direct sequencing analysis of $A B C C 9$ was performed, and a de novo mutation, c.3460C >T (p.Arg1154Trp) was found (Fig. 2A). His parents did not have this mutation. He is 6-year old now and all developmental milestones are normal, and there was no cardiac problems such as cardiomegaly or pericardial effusion.

\section{Patient 2}

Patient 2 is the first child of healthy Korean parents. She was born at 39 weeks of gestation following uncomplicated pregnancy. Her birth weight was $3.28 \mathrm{~kg}$ (25th-50th percentile), birth length was $53.1 \mathrm{~cm}$ (90th-95th percentile) and head circumference $37 \mathrm{~cm}$ (90th-95th percentile). Generalized hypertrichosis was observed at birth. At the age of 2 months, she visited a local hospital because of hairy face and body (Fig. 1). She also had systolic murmur and a sacral dimple. Echocardiography revealed a small secundum atrial septal defect (ASD), and spine ultrasonography showed a slightly thickened echogenic filum terminale. Although she had an event of febrile convulsion at 2.5 years of age, her motor and language developments were normal.

At the age of 5 years, she was referred to medical genetics clinic with excessive hirsutism and facial dysmorphisms for differential diagnosis. Her height was $108.9 \mathrm{~cm}$ (25th-50th percentile), weight was $16.5 \mathrm{~kg}$ (10th-25th percentile) and head circumference was $52.4 \mathrm{~cm}$ (90th-95th percentile). She had thick hair and generalized hypertrichosis with hair whorls on her back. Also, she had narrow forehead, epicanthal folds, and high arched palate. Under the clinical diagnosis of $\mathrm{CS}$, we performed $A B C C 9$ analysis and identified a de novo mutation c.3461G >A (p.Arg 1154GIn) (Fig. 2B). There was no significant skeletal abnormality on simple radiographs. Followup echocardiography identified mild to moderate tricuspid regurgitation and mild aortic insufficiency not requiring treatment, and confirmed the closure of ASD.

\section{Patient 3}

Patient is the second baby of healthy parents. The 5-year old elder sister did not have any medical problem. He was delivered by Cesarean section at 37 weeks and three days of gestation. During the pregnancy, amniotic fluid reduction therapy was performed twice due to severe polyhydramnios. Immediately after birth, He admitted to neonatal intensive care unit for 7 days. His birth weight was $3.52 \mathrm{~kg}$ (70th-90th percentile), birth length was $52 \mathrm{~cm}$ (90th-95th percentile). Generalized hypertrichosis and heart murmur were detected. Echocardiography found PDA and secundum ASD. Chromosome analysis using peripheral blood revealed normal male karyotype, and urine glycosaminoglycan was within normal range. At the age 4 months, he admitted to pediatric intensive care unit due to bronchopneumonia and received mechanical ventilator therapy for 3 weeks. Follow-up echocardiography showed a hypertrophic cardiomyopathy (HCMP) and pulmonary hypertension. Therefore, phosphodiesterase type 5 inhibitor and spironolactone medication was started. At the age of 7 months, he visit to medical genetics clinic for differential diagnosis of HCMP and hirsutism. His height was $69.7 \mathrm{~cm}$ (50th-75th percentile), weight was $8 \mathrm{~kg}$ (25th-50th percentile), and head circumference was $45.5 \mathrm{~cm}$ (75th-90th percentile). He showed generalized hirsutism, coarse face, high arched palate and narrow forehead. His motor development was delayed. He could roll over in both directions, however could not sit alone. Tachycardia with grade II systolic murmur and tachypnea was also accompanied.

Based on the medical history and clinical manifestation, CS was suspected and ABCC9 analysis was performed. A de novo mutation, c. 3460 C>T (p.Arg 1154Trp), was identified and CS was molecularly confirmed (Fig. 2A). He is 12 months old now, and his HCMP and pulmonary hypertension have remained stable

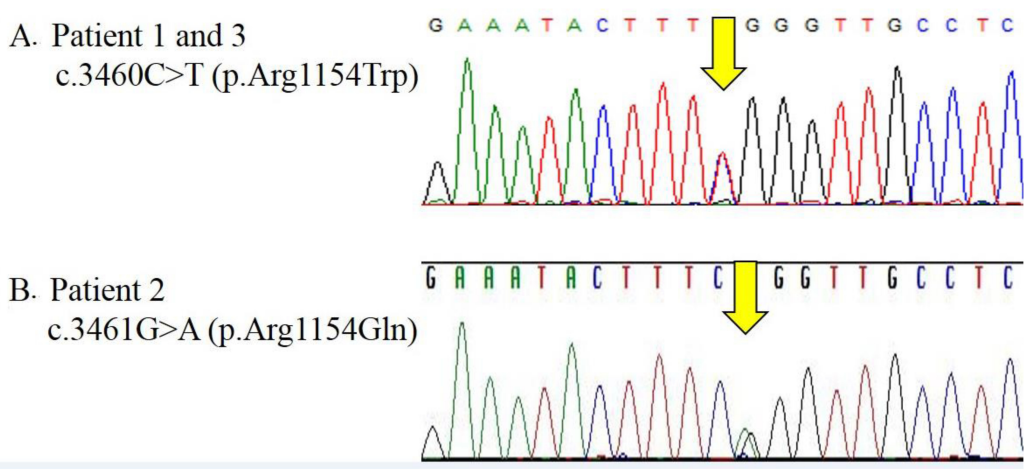

Fig. 2. Partial sequences of the $A B C C 9$ gene. (A) In Patient 1 and 3 , a heterozygous missense mutation, c.3460C $>\mathrm{T}$ (p.Arg1154Trp), leading to the substitution of arginine with tryptophan at codon position 1154 . (B) In Patient 2, a heterozygous missense mutation, c.3461G>A (p.Arg1154GIn), leading to the substitution of arginine with glutamine at codon position 1154 . 
with medications. Motor development is still delayed, however has been gradually improved.

\section{Discussion}

The common clinical findings in our three CS patients are congenital hypertrichosis and distinctive facial features (Table 1). They had no specific family history about genetic disorders. To identify differential diagnosis for coarse facial dysmorphism, we initially checked their urine glycosaminoglycan profile and peripheral blood karyotype. However, the results were normal. On the basis of congenital hypertrichosis, relative macrocephaly and distinct facial appearance, CS was postulated as clinical diagnosis. Our patients showed characterized facial features of CS such as coarse facial appearance, flat nasal bridge, arched palate, epicanthal fold as previously described [1-5]. Moreover, generalized hypertrichosis, neonatal macrosomia and macrocephaly could be important clues for CS [1]. The results of the skeletal surveys were unremarkable, except mild calvarial vault thickening and pectus carinatum shown in Patient 1. Although the majority of affected individuals have normal intelligence, mild learning disabilities and/or developmental delays have been also observed, including delay in acquisition of early motor milestones, most likely related to decreased muscle tone, and delay in speech development $[4,10]$. Our two patients (Patient 1 and 3 ) have shown similar patterns during of motor

Table 1. Clinical manifestations of three patients with Cantu syndrome in this study

\begin{tabular}{|c|c|c|c|}
\hline & Patient 1 & Patient 2 & Patient 3 \\
\hline Age/sex & $6 \mathrm{yr} / \mathrm{male}$ & 6 yr/female & 14 mo/male \\
\hline$A B C C$ mutation & $\begin{array}{l}\text { de novo } \\
\text { p.Arg1154Trp }\end{array}$ & $\begin{array}{l}\text { de novo } \\
\text { p.Arg1154Gln }\end{array}$ & $\begin{array}{l}\text { de novo } \\
\text { p.Arg1154Trp }\end{array}$ \\
\hline $\begin{array}{l}\text { Pregnancy/birth } \\
\text { Gestation } \\
\text { Birth weight (percentile) } \\
\text { Macrocephaly } \\
\text { Polyhydramnios }\end{array}$ & $\begin{array}{l}36 \text { weeks and two days } \\
>97 \text { th } \\
+ \\
+\end{array}$ & $\begin{array}{l}39 \\
25 \text { th-50th } \\
+ \\
-\end{array}$ & $\begin{array}{l}37 \text { weeks and three days } \\
70 \text { th-90th } \\
\text { Unknown } \\
+\end{array}$ \\
\hline $\begin{array}{l}\text { Growth parameter (percentile) } \\
\text { Height } \\
\text { Weight } \\
\text { Head circumference }\end{array}$ & $\begin{array}{l}>97 \text { th } \\
\text { 90th-95th } \\
>97 \text { th }\end{array}$ & $\begin{array}{l}\text { 25th-50th } \\
\text { 10th-25th } \\
\text { 90th-95th }\end{array}$ & $\begin{array}{l}\text { 50th-75th } \\
\text { 75th-90th } \\
\text { 75th-90th }\end{array}$ \\
\hline $\begin{array}{l}\text { Face } \\
\text { Coarse facial appearance } \\
\text { Narrow forehead } \\
\text { Calvarial vault thickening } \\
\text { Flat nasal bridge } \\
\text { Epicanthal folds } \\
\text { Arched palate }\end{array}$ & $\begin{array}{l}+ \\
+ \\
+ \\
+ \\
- \\
+\end{array}$ & $\begin{array}{l}+ \\
- \\
- \\
+ \\
+ \\
+\end{array}$ & $\begin{array}{l}+ \\
+ \\
- \\
+ \\
- \\
+\end{array}$ \\
\hline $\begin{array}{l}\text { Skin/hair } \\
\text { Congenital hypertrichosis }\end{array}$ & + , generalized & + , generalized & + , generalized \\
\hline $\begin{array}{l}\text { Bony anomalies } \\
\text { Osteochondrodysplasia }\end{array}$ & - & - & s \\
\hline $\begin{array}{l}\text { Heart } \\
\text { Heart function } \\
\text { PDA } \\
\text { ASD } \\
\text { Septal hypertrophy } \\
\text { Pericardial effusion } \\
\text { Pulmonary hypertension } \\
\text { Other }\end{array}$ & $\begin{array}{l}\text { Normal } \\
+ \\
- \\
- \\
- \\
-\end{array}$ & $\begin{array}{l}\text { Normal } \\
- \\
+ \\
- \\
- \\
- \\
\text { Mild TR \& Al }\end{array}$ & $\begin{array}{l}\text { Normal } \\
+ \\
+ \\
+, \text { HCMP } \\
- \\
+\end{array}$ \\
\hline $\begin{array}{l}\text { Respiratory } \\
\text { Severe infection } \\
\text { Stridor/laryngomalacia }\end{array}$ & - & $\begin{array}{l}- \\
-\end{array}$ & $\begin{array}{l}\text { +, bronchopneumonia } \\
-\end{array}$ \\
\hline $\begin{array}{l}\text { Development delay } \\
\text { Motor } \\
\text { Language }\end{array}$ & $\begin{array}{l}+, \text { improved } \\
-\end{array}$ & $\begin{array}{l}- \\
- \\
-\end{array}$ & $\begin{array}{l}+, \text { improved } \\
-\end{array}$ \\
\hline Other & Pectus carinatum & $\begin{array}{l}\text { Sacral dimple, regressed } \\
\text { febrile convulsion }\end{array}$ & \\
\hline
\end{tabular}

PDA, patent ductus arteriosus; ASD, atrial septal defect; HCMP, hypertrophic cardiomyopathy; TR, tricuspid regurgitation; Al, aortic insufficiency. 
development; however, early motor developmental delay was gradually improved during follow-up periods.

In 2006, Grange et al. [4] reported a review of the cardiac manifestations of all the previously reported CS cases. The cardiac manifestations include cardiac enlargement with increased ventricular mass and enlarged chambers, pulmonary hypertension, pericardial effusion, PDA and aortic aneurysm [4]. Although the cardiac muscle mass were increased, the cardiac function and contractility are typically normal. The incidence of PDA is about 50\%, often requiring surgical ligation in infancy $[1,4]$. There are also some cardiac manifestations observed in our patients, though all our patients had a normal cardiac function. PDA was detected in Patient 1 and 3 in their infant period, and surgical ligation was performed in Patient 1. Patient 2 had an ASD; however, it was spontaneous closed without surgical intervention. Particularly, Patient 3 showed severe pulmonary hypertension and HCMP since the age of 4 months, and has been treated with phosphodiesterase type 5 inhibitor and spironolactone. Pulmonary hypertension in CS has been reported in several infants and young children. However, the natural history has not been understood clearly [4]. One preterm Korean child with CS died due to progressive pulmonary hypertension with tricuspid and mitral regurgitation and interventricular septal wall thickening [9]. Cardiac problems are a potentially lethal association in CS. Onset and severity of each heart problem is quite variable among affected individuals, ranging from the prenatal period to young adulthood [11]. Therefore, it should be emphasized that all patients with CS require a regular and long-term cardiac monitoring and followup by echocardiography and electrocardiogram.

In the present study, we identified two pathogenic $A B C C 9$ mutations in three patients by direct sequencing. All patients are de novo cases without family history. The mutation, p.Arg 1154Trp, was recurrently found in Patient 1 and 3, and the other mutation, p.Arg 1154GIn, was identified in Patient 2. Both of them were previously reported mutations in CS $[5,6]$. Although the location of mutations was exactly identical, p.Arg 1154, distinguishable clinical variability is shown in our 3 patients. The ABCC9 gene is located on human chromosome $12 p 12.1$ and encodes the channel regulator SUR2, which is a subunit of ATP-sensitive potassium channel complex with a pore-forming potassium channel encoded by KCNJ8 or KCNJ11 $[5,8]$. Alternative RNA splicing of terminal exon of $A B C C 9$ produces two SUR2 isoforms with different tissue expression: SUR2A (expressed in cardiac and skeletal muscle) and SUR2B (expressed in vascular smooth muscle and hair follicles) [12].
Previously, mutations in $A B C C 9$ was reported in two individuals with idiopathic dilated cardiomyopathy [13]. The ABCC9 mutations may disturb the channel structure and function. And, CS-related mutations in ABCC9 reduced the ATP-mediated potassium channel inhibition, resulting in prolonged channel opening and eventually leading to some clinical features of CS such as hirsutism and cardiac abnormalities [6,9], though channel dysfunction does not explain all of the manifestation. A phenotypic overlap between CS patients and patients treated with minoxidil has been noted [3,5]. Minoxidil has been widely used for control of hypertension as well as baldness [14]. Interestingly, hirsutism and pericardial effusion are well-known side effects of minoxidil treatment. The active metabolite of minoxidil acts as an ATP-sensitive potassium channel agonist to increase potassium permeability through direct binding to the ABCC9 subunit [15]. These similarities could speculate that they have the same underlying mechanism for opening the ATP-sensitive potassium channel. Therefore, CS can be a kind of potassium channelopathy with potential therapeutic option such as ATP-sensitive potassium channel antagonist [5].

Here, we report three Korean children with CS resulting from ABCC9 mutations who show typical medical history and clinical phenotypes. Although CS is a very rare disease that mainly occurs sporadically, it can also be transmitted as an autosomal dominant condition, and familial recurrences have been also reported. Considering the concerns about development of various cardiac problems, an accurate diagnosis followed by appropriate management and genetic counseling should be provided to CS patients.

\section{Acknowledgements}

We thank the patients and their families for participating in this study. This study was supported by a grant of the Korean Health Technology R\&tD Project, Ministry of Health \& Welfare, Republic of Korea (A120030).

\section{References}

1. Grange DK, Nichols CG, Singh GK. Cantú syndrome and related disorders. 2014 Oct 2. In: Pagon RA, Adam MP, Ardinger HH, Wallace SE, Amemiya A, Bean LH et al., eds. GeneReviews ${ }^{\circledR}$ [Internet]. Seattle (WA): University of Washington, Seattle; 1993-2016. [http://www. ncbi.nlm.nih.gov/books/NBK246980/]

2. Cantú JM, Garcia-Cruz D, Sánchez-Corona J, Hernández A, Nazará Z. A distinct osteochondrodysplasia with hypertrichosis- 
Individualization of a probable autosomal recessive entity. Hum Genet 1982;60:36-41.

3. Lazalde $B$, Sánchez-Urbina R, Nuño-Arana I, Bitar WE, de Lourdes Ramírez-Dueñas M. Autosomal dominant inheritance in Cantú syndrome (congenital hypertrichosis, osteochondrodysplasia, and cardiomegaly). Am J Med Genet 2000;94:421-7.

4. Grange DK, Lorch $\mathrm{SM}$, Cole $\mathrm{PL}$, Singh GK. Cantu syndrome in a woman and her two daughters: Further confirmation of autosomal dominant inheritance and review of the cardiac manifestations. Am J Med Genet A 2006;140:1673-80.

5. van Bon BW, Gilissen C, Grange DK, Hennekam RC, Kayserili H, Engels

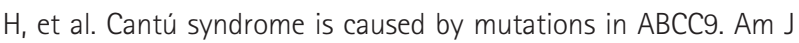
Hum Genet 2012;90:1094-101.

6. Harakalova M, van Harssel JJ, Terhal PA, van Lieshout S, Duran K, Renkens I, et al. Dominant missense mutations in ABCC9 cause Cantú syndrome. Nat Genet 2012;44:793-6.

7. Brownstein CA, Towne MC, Luquette $\sqcup$, Harris DJ, Marinakis NS, Meinecke $P$, et al. Mutation of KCNJ8 in a patient with Cantú syndrome with unique vascular abnormalities - support for the role of K(ATP) channels in this condition. Eur J Med Genet 2013;56:67882.

8. Nichols CG. KATP channels as molecular sensors of cellular metabolism. Nature 2006;440:470-6.
9. Park JY, Koo SH, Jung YJ, Lim YJ, Chung ML. A patient with Cantú syndrome associated with fatal bronchopulmonary dysplasia and pulmonary hypertension. Am J Med Genet A 2014;164A:2118-20.

10. Scurr I, Wilson L, Lees $M$, Robertson $S$, Kirk E, Turner $A$, et al. Cantú syndrome: report of nine new cases and expansion of the clinical phenotype. Am J Med Genet A 2011;155A:508-18.

11. Hiraki $Y$, Miyatake $S$, Hayashidani $M$, Nishimura $Y$, Matsuura $H_{1}$ Kamada $\mathrm{M}$, et al. Aortic aneurysm and craniosynostosis in a family with Cantu syndrome. Am J Med Genet A 2014;164A:231-6.

12. Bryan J, Muñoz $A$, Zhang $X$, Düfer $M$, Drews $G$, Krippeit-Drews $P$, et al. $A B C C 8$ and $A B C C 9: A B C$ transporters that regulate $K+$ channels. Pflugers Arch 2007;453:703-18.

13. Bienengraeber $M$, Olson $T M$, Selivanov VA, Kathmann EC, O'Cochlain F, Gao F, et al. ABCC9 mutations identified in human dilated cardiomyopathy disrupt catalytic KATP channel gating. Nat Genet 2004;36:382-7.

14. Messenger AG, Rundegren J. Minoxidil: mechanisms of action on hair growth. Br J Dermatol 2004;150:186-94.

15. Schwanstecher M, Sieverding C, Dörschner H, Gross I, Aguilar-

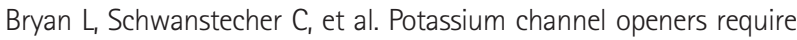
ATP to bind to and act through sulfonylurea receptors. EMBO J 1998;17:5529-35. 